\title{
EDUCAÇÃO EMPREENDEDORA NO ENSINO PROFISSIONAL: DESAFIOS E EXPERIÊNCIAS NUMA INSTITUIÇÃO DE ENSINO
}

\author{
D. C. GOMES*, L. A. F. SILVA \\ Instituto Federal de Educação, Ciência e Tecnologia do Rio Grande de Norte \\ *danilo.cortez@ifrn.edu.br
}

Submetido 25/10/2016 - Aceito 23/01/2018

DOI: $10.15628 /$ holos.2018.5264

\begin{abstract}
RESUMO
A educação empreendedora é uma ferramenta importante a ser disseminada entre as instituições de ensino, especialmente aquelas que atuam na educação profissional. Assim, o objetivo desse estudo foi diagnosticar e analisar a percepção dos alunos em relação às suas experiências nesta instituição, dentre estas, com a disciplina Gestão Organizacional. O empreendedorismo jovem no sentido amplo, em que exemplos práticos e ferramentas úteis são apresentados e utilizados pelos alunos, apresenta-se como forma de inclusão de jovens no mercado de trabalho e em contrapartida é fator preponderante para promoção do desenvolvimento socioeconômico brasileiro (LIMA-
\end{abstract}

FILHO, SPROESSER e MARTINS, 2009; BULGACOV, 2010). Nesse sentido, esta pesquisa de natureza exploratória e descritiva utilizou um questionário com perguntas abertas e fechadas para a coleta de dados, seguido por uma análise quantitativa e qualitativa. Os questionários foram aplicados junto aos alunos dos cursos técnico integrado em alimentos e informática (nível médio turmas concluintes do 4ㅇ ano) nos anos de 2012, 2013 e 2014 do IFRN - Campus Currais Novos, que cursaram a disciplina Gestão Organizacional, totalizando 215 alunos que compuseram o universo pesquisado. Os resultados indicaram que a experiência na instituição, bem como com a didática utilizada na disciplina, foram positivas.

PALAVRAS-CHAVE: Empreendedorismo, educação empreendedora, ensino profissional.

\section{ENTREPRENEURIAL EDUCATION IN PROFESSIONAL EDUCATION: CHALLENGES AND EXPERIENCES IN EDUCATIONAL INSTITUTION}

\begin{abstract}
ABSTRAC
The entrepreneurial education is an important tool to be disseminated among educational institutions, especially those who work in professional education. The objective of this study was to diagnose and analyze the students' perception in relation to their experiences in this institution, among them, with the discipline Organizational Management. The youth entrepreneurship in a broad sense in which practical examples and useful tools are presented and used by students, is presented as a way to include young people in the labor market, and on the other hand is a preponderant factor for promotion of brazilian socioeconomic development (LIMA-FILHO, SPROESSER e MARTINS, 2009; BULGACOV, 2010). In
\end{abstract}

\begin{abstract}
this sense, this exploratory and descriptive research used a questionnaire with open and closed questions for the collect data, followed by a quantitative and qualitative analysis. The questionnaires were applied with the students of the integrated technical courses in food and information technology (high school graduating classes of the 4th year) in the years 2012, 2013 and 2014 IFRN - Campus Currais Novos, who attended the discipline Organizational Management, totalizing 215 students who composed the group studied. The results indicated that the experience in the institution as well as with the teaching used in the discipline were positive.
\end{abstract}

KEYWORDS: Entrepreneurship, entrepreneurial education, professional education. 


\section{INTRODUÇÃO}

Este artigo busca abordar a temática do empreendedorismo relacionado à educação, isto é, verificar como um método de ensino denominado educação empreendedora pode disseminar assuntos inerentes ao mercado de trabalho e a criação de empresas, de forma dinâmica e eficiente. Ressalta-se que essa abordagem didática tem sido cada vez mais necessária nas mais diversas modalidades de ensino.

Pode-se dizer que alguns fatores são predominantes para justificar o desenvolvimento dessa pesquisa, a saber: a necessidade de dinamizar a relação professor e aluno no contexto de sala de aula; a importância de abordar a temática do empreendedorismo para futuros profissionais que estarão inseridos no mercado de trabalho; além da urgência em viabilizar o contato desses discentes no mundo "real" empresarial.

Desse modo, compreender a percepção desses alunos em relação ao ensino-aprendizagem da disciplina ministrada com base numa educação empreendedora, permite aos pesquisadores e por que não dizer, a própria instituição - objeto de estudo - ter subsídios importantes para diálogos com outras disciplinas e profissionais da educação, sem contar no feedback obtido pelo professor pesquisador quanto ao trabalho desenvolvido com seus alunos, que tem uma perspectiva dinâmica e diferenciada.

Um dos maiores desafios atuais quanto se trata de educação consiste na forma como os conteúdos devem ser transmitidos aos alunos, havendo discordâncias consideráveis entre pesquisadores da área. Entretanto, a utilização de dinâmicas e atividades específicas que tornem determinados conteúdos mais atrativos e ao mesmo tempo, despertam a curiosidade dos discentes, é importante e necessária no atual contexto educacional (HENGEMÜHLE, 2014).

Além do mais, tem-se as mudanças oriundas da reforma do ensino médio e toda sua estrutura curricular, o que justifica ainda mais considerar os dados aqui expostos. Salienta-se, ainda, que tendo em vista a expansão da rede federal de educação profissional no Brasil, por meio dos Institutos Federais, constata-se o crescimento considerável da oferta de oportunidades para um público que, além de um ensino de qualidade, tem a chance de adquirir uma formação técnica e profissional (BRASIL, 2016). No entanto, será que apenas a oferta de vagas e o oferecimento de cursos, como no caso dos eixos tecnológicos de alimentos e informática no IFRN - Campus Currais Novos, tem feito com que os alunos e futuros profissionais, tenham acesso a métodos de ensino diferenciados dos já existentes? Estão tendo eles oportunidades de interagir com o mercado de trabalho, no qual estarão em breve inseridos?

Dito isto, tem-se como problemática central desta pesquisa: Qual a percepção dos alunos concluintes nos anos 2012 a 2014 dos cursos técnicos integrados de nível médio do IFRN - Campus Currais Novos - em relação às suas experiências nesta instituição de ensino, em particular, com a disciplina Gestão Organizacional ministrada com base numa educação empreendedora? Assim, para responder tal indagação, esse estudo tem como objetivo principal diagnosticar e analisar a percepção dos alunos concluintes nos anos 2012 a 2014 dos cursos técnicos integrados de nível médio do IFRN - Campus Currais Novos - em relação às suas experiências nesta instituição de 
ensino, em particular, com a disciplina Gestão Organizacional ministrada com base numa educação empreendedora.

\section{REVISÃO BIBLIOGRÁFICA}

As diversas temáticas (criação de novos negócios, perfil profissional competitivo etc.) que estão pautadas no empreendedorismo, não são tão recentes, e no Brasil, pelo menos nas duas últimas décadas, esse assunto passou a ser discutido com mais ênfase (DOLABELA, 1999), seja por parte das ciências sociais aplicadas, como a administração, ou em outras áreas que passaram a abordar suas ações tendo por base o empreendedorismo, como as ciências sociais que trazem a necessidade de discutir o empreendedorismo social, isto é, a forma como essas características inovadoras e eficientes podem colaborar com projetos com alcance social e não meramente privado. Vale ressaltar que "formar pessoas competentes e empreendedoras também irá contribuir para diminuir as sequelas sociais que distanciam ricos e pobres. Portanto, abordamos o tema sob a ótica na qual a educação possa contribuir sistematicamente na formação de pessoas social, ecológica e economicamente responsáveis" (HENGEMÜHLE, 2014, p. 29).

Nessa perspectiva, o empreendedorismo passa não só a constar como disciplina obrigatória ou optativa nas grades curriculares dos mais diversos cursos de ensino superior, ensino médio e educação básica, mas chega também na atuação do docente enquanto empreendedor, ou seja, por meio de metodologias próprias, esses conhecimentos são transmitidos de forma dinâmica e instigante denominada educação empreendedora. De acordo com Filion (1999), esse processo de ensino distingue-se do tradicional por se pautar principalmente nas ações dos próprios alunos, contextualizando-os no mundo em que o mesmo está inserido, alertando-os para os desafios existentes e ao mesmo tempo preparando-os para as intempéries próprias de um mercado altamente competitivo, como a falta de recursos e investimentos, as incertezas típicas relacionadas ao início de uma carreira ou de um novo negócio.

Essa tentativa de mudança do status quo no ensino desses conteúdos implicam uma mudança de paradigma, que deve ocorrer de acordo com as exigências do complexo e exigente ambiente organizacional, levando-se em consideração das inúmeras dificuldades que se deparam aqueles profissionais que assim consideram urgente essa dinâmica da educação empreendedora, pois "os valores do nosso ensino não sinalizam para o empreendedorismo, estando voltados, em todos os níveis, para a formação de profissionais que irão buscar emprego no mercado de trabalho" (DOLABELA, 1999, p. 35). Além do mais, comumente se encontra outra característica muito disseminada nos cursos profissionalizantes e do ensino superior, que evidenciam demasiadamente o que Dolabela (1999) denomina de "cultura da grande empresa", isto é, quando os exemplos e contextos abordados são inerentes às grandes empresas e não de acordo com a realidade local dos alunos, excluindo as características peculiares das micro e pequenas empresas da região.

O pensamento do autor destacando a importância da educação empreendedora corrobora com a percepção de Drucker (1986, p. 349) quando afirma que "a inovação e o espírito empreendedor são, portanto, necessários na sociedade tanto quanto na economia; na instituição de serviço público tanto quanto em empresas privadas". 
De fato, essa educação empreendedora que atinge principalmente o público estudantil jovem, tem-se solidificado como mecanismo de tentar despertar nesses alunos a importância sobre a inclusão no mercado de trabalho, seja como um profissional empregado com características distintas da grande maioria ou então como empreendedores que se tornam empregadores, tornando-se assim, um fator preponderante para promoção o desenvolvimento socioeconômico brasileiro (LIMA-FILHO, SPROESSER e MARTINS, 2009; BULGACOV, 2010), pois a educação empreendedora dissemina princípios que auxiliam no alcance de resultados em curto, médio e longo prazo, dependendo das circunstâncias e contextos em que se inserem os atores envolvidos nesse tipo de dinâmica, em especial, os jovens que possuem uma questão e desafio essencial, isto é, "saber o que fazer para aproveitar a nova onda de profissões do futuro" (MENDES e FILHO, 2012, p. 40).

Nessa mesma linha de raciocínio, Drucker (1986, p. 361) ressalta que "em uma sociedade empreendedora, os indivíduos enfrentam um enorme desafio, desafio este que precisam explorar como sendo uma oportunidade: a necessidade por aprendizado e reaprendizado continuados". Para tanto, essas oportunidades precisam ser descobertas, e ao serem vistas e descobertas, precisam ser aproveitadas. Conforme Dolabela e Filion (2013, p. 136), urge uma mudança pautada nesse desafio acima descrito que envolve primordialmente a educação com base no empreendedorismo.

Se a sociedade deve mudar devemos colocar em prática abordagens revolucionárias - e até mesmo radicais - que permitam que essa mudança aconteça. Na perspectiva do empreendedorismo a mudança deve começar pela base e não pelo topo. Mas antes de tudo as mudanças estruturais que irão gerar as mudanças empresariais desejadas devem ser integradas ao sistema social. O empreendedorismo oferece novas perspectivas para modificar os padrões e processos de aprendizagem existentes. Ele revela um segredo tão antigo quanto a própria civilização: a capacidade dos seres humanos serem os protagonistas do seu próprio destino está se tornando acessível a todos, seja em sociedades menos desenvolvidas ou em estruturas sociais organizadas e sofisticadas.

Contudo, essa "revolução educacional" não ocorre de forma instantânea, pois se devem levar em consideração várias características específicas, a começar pela correta compreensão das necessidades dos empreendedores, bem como entender a maneira como as instituições de ensino encaram esses desafios e ao mesmo tempo, disponibilizam uma formação própria voltada para o empreendedorismo com base numa educação empreendedora, que se preocupa em atender também o desenvolvimento integral do indivíduo, a partir das dimensões cognitivas, afetivas e emocionais, como apregoado por Hengemühle (2014), no intuito de que essas pessoas possam enfrentar de forma adequada, profissional e competitiva, o universo incerto e turbulento que o espera (LIMA-FILHO, SPROESSER e MARTINS, 2009).

Para Rabbior apud Lopes (2010), os objetivos da educação empreendedora envolvem a conscientização sobre o empreendedorismo e a carreira empreendedora, que deve lançar sementes para o futuro; influenciar e desenvolver atitudes, habilidades e comportamentos empreendedores; desenvolver qualidades pessoais relacionadas às competências necessárias para o mundo moderno, tais como: criatividade, assumir risco e assumir responsabilidade; incentivar e desenvolver empreendedores, principalmente por meio da estimulação de criação de novos 
negócios e iniciativas, apoiando integralmente o desenvolvimento destas; gerar empregos; desenvolver conhecimentos, técnicas e habilidades focados no mundo dos negócios e necessários para a criação de uma empresa; além de auxiliar empreendedores e empresas, através de conhecimento e ferramentas, a melhorar sua competitividade.

Segundo Filion (1993, p. 61),

a educação para o empreendedor deve auxiliar o indivíduo, no seu desenvolvimento, pelo reforço de suas características diferenciadas. Em certo sentido, isto se assemelha à educação para liderança, principalmente por dar apoio, ao invés de pressionar até se obter a conformidade. Deve ser pró-ativa e não estar centrada em um único método. Deve apresentar aos empreendedores em potencial, formas para definir visões e maneiras de projetar os sistemas de relações e de aprendizado, necessários para levar as visões adiante.

Em outro trabalho, Filion (1991) define um empreendedor como uma pessoa que imagina, desenvolve e realiza visões. Assim, desenvolver essas habilidades num indivíduo requer cuidado e métodos específicos para que os objetivos sejam realmente alcançados, tal qual a metodologia denominada Oficina do Empreendedor, elaborada e disseminada por Dolabela (1999). Neste tipo de metodologia, o professor tem papel significativo, pois este assume "a função de criador do ambiente favorável ao desenvolvimento do empreendedor. Ele passa a ser organizador da cultura empreendedora e abandona as antigas funções de mediador do conhecimento" (DOLABELA, 1999, p. 111). Um exemplo pode ser visto em Gomes et al. (2014) que desenvolveu ações com base nessa metodologia por meio de atividades que articulavam ensino e extensão, gerando resultados bem interessantes.

Em contrapartida, Hengemühle (2014), evidencia que, no Brasil, ainda há uma distância substancial entre o idealizado e o necessário em relação às práticas pedagógicas desenvolvidas no atual ensino. Ao mesmo tempo, o autor afirma que o ensino do empreendedorismo com base numa educação empreendedora é uma das vertentes a serem utilizadas como propulsor de mudanças:

a formação do perfil de empreendedor, acreditamos, tem origens na personalidade e contribuição do meio cultural em que o sujeito vive. No entanto, também temos a conviç̧ão de que o processo educacional pode ajudar a despertar e a desenvolver esse perfil. Nesse sentido, os professores investigados chamam atenção de que a academia tem o compromisso de contribuir na construção do conceito de empreendedorismo a partir dos valores e princípios organizadores da sociedade atual (HENGEMÜHLE, 2014, p. 29).

Dolabela (1999) também aponta razões plausíveis para que a cultura empreendedora seja disseminada, pois esta estimula a autorrealização e o desenvolvimento, incidindo no desenvolvimento local, apoiando a pequena empresa, ampliando a base tecnológica, respondendo ao desemprego, apontando armadilhas a serem evitadas, bem como auxiliando numa reorientação do ensino brasileiro.

Não raramente surgem questionamentos a respeito da possibilidade de aprender a ser empreendedor e até que ponto a educação empreendedora é capaz de formar novos 
empreendedores. Sobre essa celeuma, Filion (2003, p. 16) diz que "é possível aprender o empreendedorismo. E a aprendizagem se realiza de uma maneira muito gradual". Para Dolabela (1999), não há resultados científicos que apontem se é possível ensinar alguém a ser um empreendedor, todavia, entende-se que é possível aprender a sê-lo, desde que os subsídios e suportes necessários sejam disponibilizados a contento (FILION, 2004). Destaca-se, no entanto, que há um consenso no entendimento de que a maneira mais adequada e eficiente de ensinar o empreendedorismo é por meio da realidade educacional, ou seja, através de uma educação empreendedora que relacione conteúdo teórico e prático com base em exemplos reais do mundo do trabalho.

\section{METODOLOGIA}

Esta pesquisa, de natureza exploratória e descritiva, utilizou um questionário com perguntas abertas e fechadas (por meio de uma escala de Likert) para a coleta de dados, seguido por uma análise quantitativa e qualitativa, a partir da qual foram confeccionados Figuras e quadros que ilustram de forma mais adequada os dados coletados.

De acordo com Trivinos apud Zanella (2006), a pesquisa é exploratória porque tem como finalidade ampliar o conhecimento a respeito de um determinado assunto, ao passo que é descritiva porque procura conhecer a realidade estudada, destacando minuciosamente os fatos e fenômenos observados.

Inicialmente, foi realizado um levantamento bibliográfico na tentativa de adquirir informações a respeito da temática proposta, com foco na educação empreendedora e suas diversas metodologias utilizadas em sala de aula atualmente no Brasil, bem como de experiências e projetos desenvolvidos sobre o assunto, sem esquecer os desafios subjacentes.

Um ponto interessante dessa pesquisa que ocorreu durante 3 anos se dá pelas diversas atividades que foram desenvolvidas, sempre em busca de despertar nos alunos o interesse sobre o empreendedorismo. Nesse contexto, o ensino com base na educação empreendedora gerou ações bem dinâmicas que possibilitaram o envolvimento integral das turmas. Dessa forma, além das aulas teóricas, visitas a pequenas e grandes empresas foram um ponto decisivo nesse período. Não apenas pela visita em si, mas pela troca de informações com esses empreendedores ou empresários já consolidados em suas regiões.

$\mathrm{Na}$ oportunidade, o docente titular da disciplina desenvolveu junto com as turmas, um projeto de extensão intitulado "Empreendedorismo Jovem: da escola para o mercado de trabalho", o que proporcionou momentos bastante interessantes para os discentes. O projeto tentou diminuir a distância entre a escola e as empresas locais, permitindo aos alunos conhecerem um pouco mais de perto a realidade das empresas, com suas potencialidades e desafios constantes. Nesse mesmo projeto, empreendedores "ocultos" também puderam falar de sua labuta e criatividade, justamente aqueles que nem sempre são vistos como empreendedores por boa parte da sociedade.

Em outros momentos, foram realizadas visitas a organizações sem fins lucrativos de Currais Novos, pois tem-se a convicção do empreendedor passa também pelas dimensões afetivas e 
emocionais. Desse modo, foram parceiros dessas ações o Centro de Dependentes Químicos Ágape, o Abrigo de Idosos Mons. Paulo Herôncio, a Casa do Pobre, a Associação de Pais e Amigos dos Excepcionais e o Centro de Referência de Assistência Social.

No entanto, a atividade mais específica que auxiliou no despertar sobre o empreendedorismo foi o trabalho de criação de novas empresas/produtos, realizadas em todas as turmas, que reunidas em grupos, criavam seus planos de negócios e modelos de negócio (através do método (ANVAS), com base em oportunidades percebidas pelos alunos no tocante a região em que residiam. Esses trabalhos se tornam uma espécie de "Hotel de Projetos" que tem gerado resultados muito positivos, além de gerar uma expectativa muito salutar nos discentes.

O referencial teórico foi utilizado em todos os estágios da pesquisa, haja vista o número crescente de ideias, projetos e iniciativas abordadas em locais distintos do país.

A pesquisa foi realizada no IFRN - Campus de Currais Novos, localizado na Rua Manoel Lopes Filho, 773 - Bairro Manoel Salustino - Currais Novos/RN. A população-alvo se constituiu de todos os alunos dos cursos técnicos integrados que cursavam o 4 ano nos períodos de 2012, 2013 e 2014, nas turmas de informática e alimentos, totalizando 215 alunos. Por isso, esta pesquisa se caracteriza como uma pesquisa do tipo censitária. Sobre pesquisa censitária, Zanella (2006) enfatiza que esse tipo de pesquisa não deve se utilizar a amostragem. Como instrumentos de coleta de dados, utilizou-se a observação direta intensiva e a aplicação de questionário.

Os questionários foram aplicados junto a estes alunos dos cursos técnicos integrados em alimentos e informática, que cursaram a disciplina Gestão Organizacional, que tinha a educação empreendedora como fonte de métodos e instrumentos a serem trabalhados em sala de aula e fora dela. As aplicações desses questionários ocorreram sempre ao final da disciplina citada, isto é, ao final de cada ano letivo, caracterizando-se por um estudo longitudinal. Pode-se dizer que a pesquisa teve início no dia 1ㅇ de outubro de 2012 com término 27 de fevereiro de 2015.

\section{RESULTADOS E DISCUSSÕES}

De fato, a maioria dos alunos que ingressam em uma instituição de educação profissional cujos cursos são prioritariamente técnicos, porém, sem descuidar do ensino nas suas concepções mais abrangentes, entra com muitas expectativas em relação a sua formação propriamente dita, todavia, resta saber se essas escolas estão não apenas aptas, mas disponíveis e formadas para suprir as expectativas apresentadas por esses alunos. Desse modo, com o intuito de identificar a percepção dos alunos do Instituto Federal de Educação Ciência e Tecnologia do Rio Grande do Norte - Campus Currais Novos sobre essa missão institucional, ao serem questionados sobre em que nível suas expectativas foram supridas, estes responderam de forma positiva, conforme a Figura 1. Percebe-se que $45,6 \%$ dos alunos consideraram ótimo o atendimento de suas expectativas, percentual relevante levando em conta os diversos desafios enfrentados por um aluno do curso de nível médio integrado, a saber, dificuldade de conciliação entre as matérias convencionais do ensino médio e as disciplinas técnicas, deslocamento de cidades vizinhas, greves que ocorreram no período da pesquisa, etc. Esses dados tornam-se ainda mais relevantes quando levados em consideração as expectativas dos alunos de forma geral em relação aos cursos em que estão vinculados e suas respectivas pretensões profissionais futuras. 


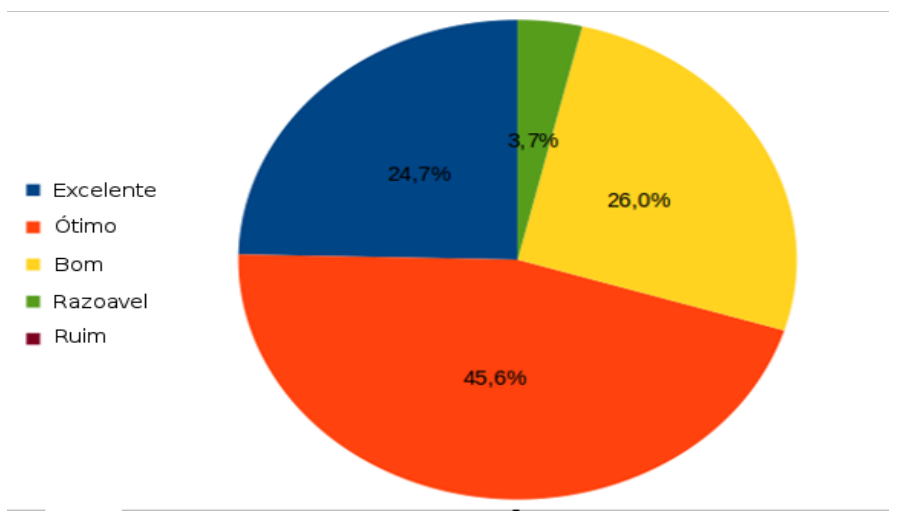

Figura 1: Nível em que suas experiências iniciais ao ingressar no curso foram supridas Fonte: Dados da pesquisa, 2015.

Outro fator que deve ser observado é que, por desconhecerem o projeto pedagógico do curso, isso muitas vezes por desinteresse propriamente dito, essa relação entre as expectativas dos alunos versus instituição pode se tornar latente, haja vista a impossibilidade da instituição atender todas as expectativas oriundas de alunos tão diferentes no que tange à personalidade, histórias de vida, pretensões profissionais, etc.

Na Figura 2, observa-se a distribuição entre os alunos que pretendem continuar na área do curso técnico integrado em que eles estão vinculados. Destes, 35,2\% manifestaram o desejo de continuar na área, o que pode-se dizer que é um percentual relativamente baixo, o que corrobora com outros dados que serão apresentados e analisados mais adiante, dentre eles, que uma parte dos alunos entram nos cursos técnicos profissionalizantes da rede federal de ensino profissional com o objetivo de usufruir de um ensino de qualidade, especialmente nas disciplinas do ensino médio, cujo objetivo maior é a aprovação em exames nacionais de admissão para o ensino superior, e não necessariamente a formação técnica ofertada pela instituição de ensino. Assim, é comum certo desconhecimento das particularidades do curso e não raramente, a desistência de continuidade na área de formação técnica, ou seja, muitos dos alunos que entram com o desejo de se qualificarem como profissionais de determinada área acabam desistindo dessa ideia.

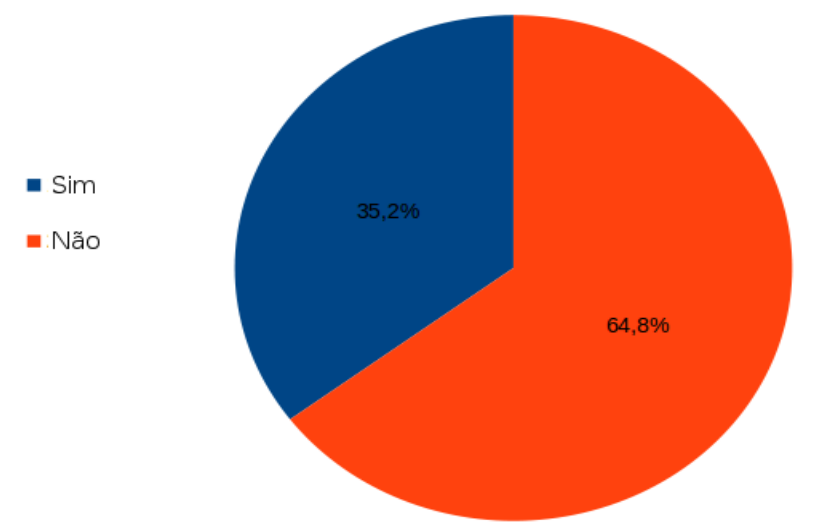

Figura 2: Distribuição de alunos que pretendem continuar na área do curso técnico profissionalizante

Fonte: Dados da pesquisa, 2015. 
Um dado interessante obtido a partir da Figura 3 é que apesar dos 35,2\% dos alunos demonstrarem interesse em continuar na área do seu curso, como visto anteriormente, um percentual substancial $(90,6 \%)$ afirma que sua formação técnica pode ser qualificada como boa, ótima ou excelente. Nesse sentido, vê-se que mesmo optando por não seguir na sua área de formação técnica, os alunos saem capacitados para atuar no mercado de trabalho, mesmo que provisoriamente, para, por exemplo, se manter na faculdade.

- Excelente

n ótimo

10: Bom

- Razoavel

- Ruim

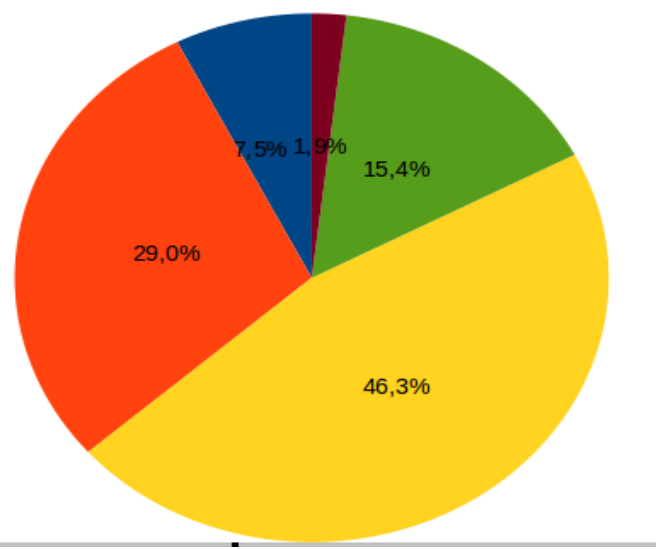

Figura 3: Grau de formação adquirida pelos alunos ao termino do curso Fonte: Dados da pesquisa, 2015.

Na Figura 4, os alunos apresentaram as principais dificuldades na sua formação técnica. A resposta com maior percentual foi a falta de interesse do aluno, o que apenas reforça o que já foi apresentado anteriormente, quando dito que muitos alunos ingressam nos cursos técnicos almejando apenas a oferta com qualidade das disciplinas comuns ou propedêuticas do ensino médio, não possuindo muito interesse pelas disciplinas técnicas, tornando assim o seu processo de aprendizado mais árduo e gerando, por exemplo, novos desafios para o professor dessas disciplinas.

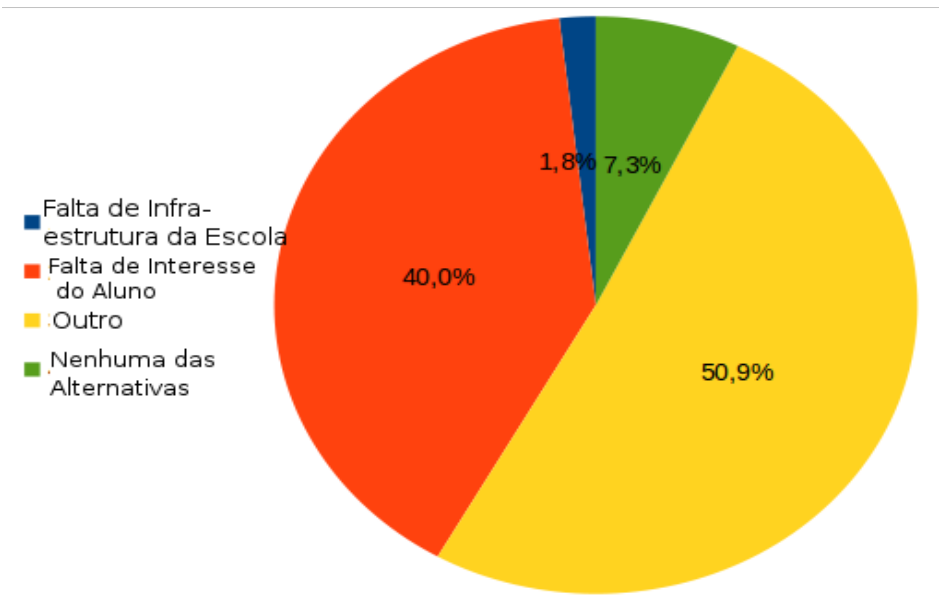

Figura 4: Principais dificuldades enfrentadas na sua formação técnica Fonte: Dados da pesquisa, 2015. 
No que tange às perspectivas desses alunos enquanto futuros profissionais das áreas técnicas em que estão sendo formados, a Figura 5 apresenta resultados interessantes, pois os respondentes conseguem visualizar oportunidades no mercado de trabalho.

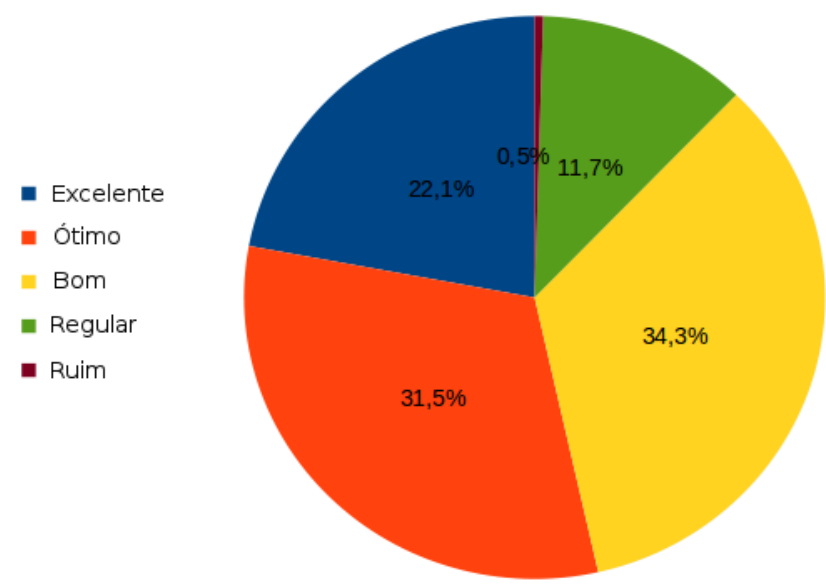

Figura 5: Perspectiva de um técnico de informática ou alimentos no atual mercado de trabalho Fonte: Dados da pesquisa, 2015.

É válido lembrar que ao serem questionados, não foi especificada uma abrangência geográfica aos alunos, portanto, as respostas podem ter as mais variadas influências como a de um mercado mais denso e propício a determinada formação técnica, quanto a uma realidade interiorana, como na cidade de origem dos próprios alunos, que nem sempre apresenta muitas oportunidades de emprego. Todavia, mesmo diante disso, as respostas ainda são animadoras, levando em conta que apenas $0,5 \%$ veem como ruins as perspectivas para o mercado de trabalho de um técnico em informática e $22,1 \%$ entendem estas como ótimas. Essa visão pode estimular os alunos a tentarem seguir na área como uma fonte de segurança, inclusive numa perspectiva de formação de ensino superior.

Abaixo segue uma breve lista das dificuldades enfrentadas por um técnico em alimentos ou informática, sendo estas consideradas mais relevantes pelos alunos. Essa lista está na ordem de relevância elaborada pelos respondentes:

- Dissonância entre a teoria aprendida e a prática utilizada nas empresas;

- Falta de consciência das empresas quanto à necessidade de um profissional técnico na área;

- Baixa remuneração;

- Poucas oportunidades de emprego.

Vale destacar que a dificuldade mais relevante apontada pelos alunos foi a dissonância entre a teoria aprendida em sala de aula e a prática observada em empresas que foram visitadas. Dessa forma, pode-se levantar a hipótese de que existem algumas lacunas nas disciplinas ofertadas que não abordam, segundo a opinião dos alunos, questões relacionadas ao cotidiano das empresas. Aqui tem-se uma questão delicada, pois nem sempre as empresas agem de acordo com a legislação em vigor, conteúdo que é abordado em sala de aula, por exemplo. Em 
contrapartida, esses dados devem servir como ponto de reflexão para a instituição e principalmente para aqueles que lecionam disciplinas técnicas para que seus conteúdos possam se aproximar o máximo possível da realidade organizacional, ou seja, para que o futuro profissional possa, em sala de aula, estar mais perto de um contexto que em breve será por ele enfrentado.

Na Figura 6, vê-se as respostas dos alunos ao serem questionados sobre a experiência de ensino no IFRN. Esses dados são bem positivos em relação à instituição, cujo percentual de $58,2 \%$ qualifica como excelente sua experiência no IFRN - Campus Currais Novos. Por outro lado, nenhum aluno questionado considerou essa mesma experiência como ruim, corroborando ainda mais a qualificação contrária, ou seja, ótica ou excelente.

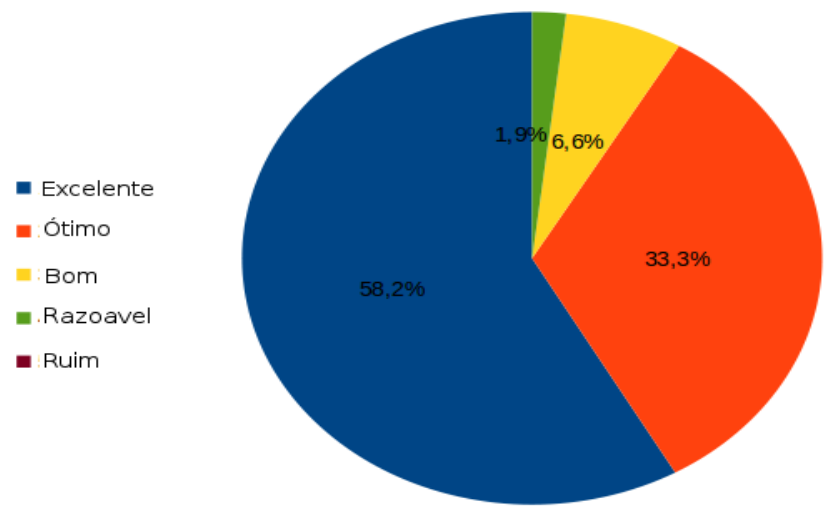

Figura 6: Experiência de ensino no IFRN. Fonte: Dados da pesquisa, 2015.

Ao serem questionados sobre se indicariam ou não a um amigo ou parente a cursarem o nível médio integrado no IFRN, como mostra a Figura 7, 95,9\% dos alunos disseram que indicariam. Esse percentual reflete a qualidade de ensino oferecido pela instituição. Os 4,1\% que afirmaram não indicar e ao justificarem suas respostas, majoritariamente disseram que o ritmo acadêmico é muito puxado e nem todos conseguiriam se adaptar.

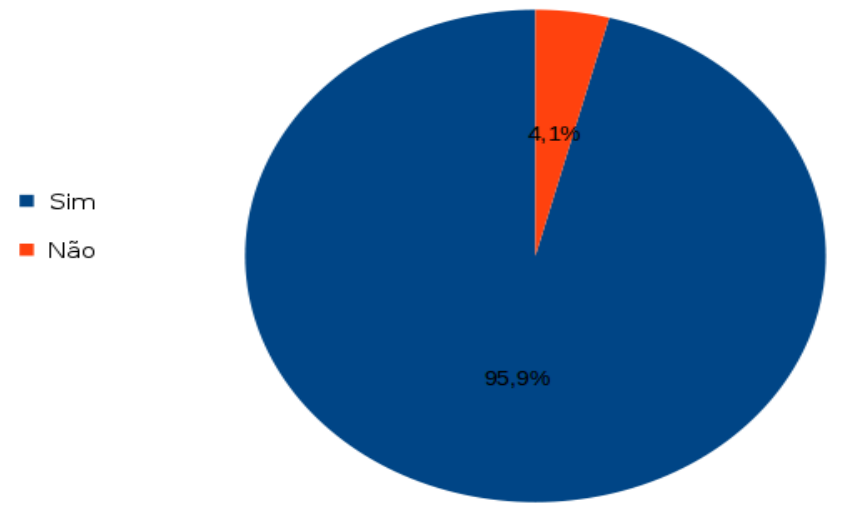

Figura 7: Indicaria a um(a) amigo(a) ou parente o curso de nível médio integrado do IFRN? Fonte: Dados da pesquisa, 2015.

Na questão seguinte, os alunos foram interrogados a respeito dos cursos de nível superior do IFRN - Campus Currais Novos a saber: licenciatura em Química, Tecnologia em Alimentos e Tecnologia em Sistemas para Internet. 


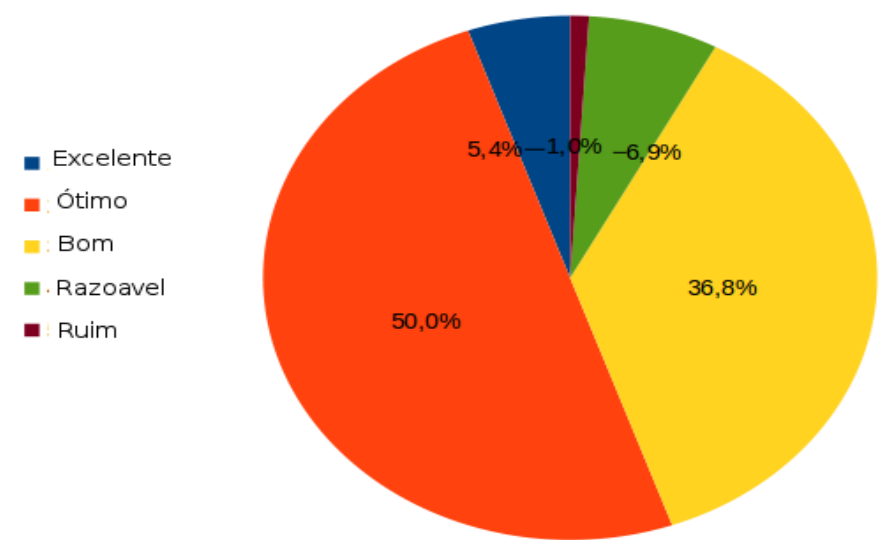

Figura 8: Opinião a respeito dos cursos de tecnologia de nível superior do IFRN - Campus Currais Novos Fonte: Dados da pesquisa, 2015.

Ao contrário das outras respostas vistas até o momento, essas não trouxeram uma percepção muito otimista dos alunos no que tange a oferta da instituição, pois muitos ainda demonstram um pouco de receio em relação aos cursos de nível superior ofertados, visto que as respostas não foram tão hegemônicas. Nesse quesito, deve ser levado em consideração o tempo curto dos cursos até então ofertados, bem como um número limitado dessa oferta, diferentemente de um grande campus que possui dezenas de cursos para escolha desses alunos. De todo modo, se for observado os dados apresentados na Figura 2 que trata do percentual dos alunos que desejam continuar na área de sua formação técnica, esses dados ora apresentados em relação aos cursos superiores não são tão desanimadores. Entende-se que a consolidação desses cursos superiores trará um atrativo maior para esses alunos concluintes do ensino médio.

Posteriormente foi pedido aos alunos que avaliassem a influência do IFRN no processo de aprendizado para os resultados nas provas de avaliação para ingresso no ensino superior, como no caso do ENEM - Exame Nacional do Ensino Médio. Logo abaixo na Figura 9, percebe-se que mesmo o objetivo principal do IFRN não sendo preparar para essas provas e sim formar excelentes profissionais, que tenham um senso crítico da realidade, os alunos reconheceram uma influência muito positiva da instituição nesse processo, ou melhor, na aprendizagem para a realização dessas provas. 


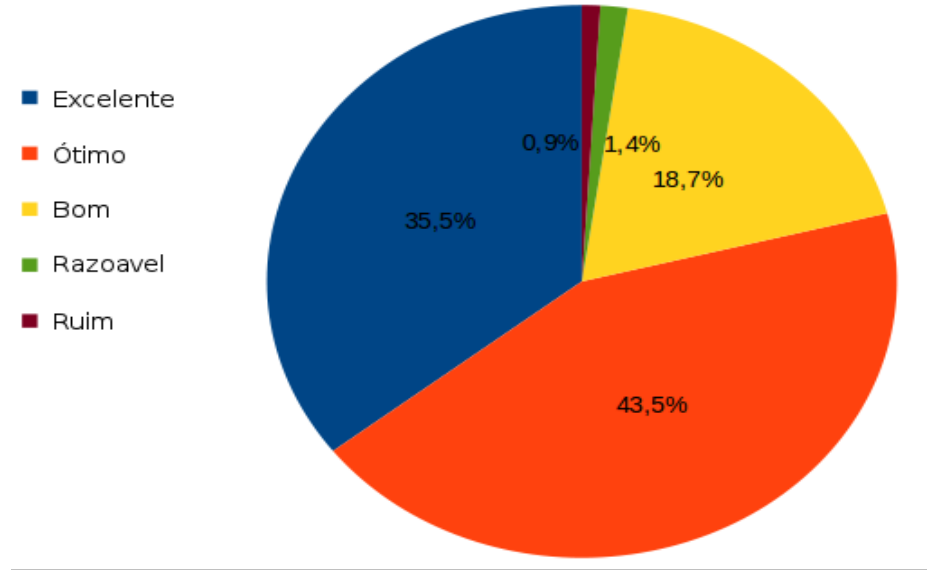

Figura 9: Contribuição do IFRN no processo de aprendizagem para o Vestibular e ENEM. Fonte: Dados da pesquisa, 2015.

Já, ao serem questionados sobre a influência negativa da instituição no seu aprendizado, durante o 4ㅇa ano do ensino médio técnico na modalidade integrado, isto é, no último ano de sua formação na instituição, 59,5\% afirmaram que ouve uma influência negativa, conforme Figura 10, especialmente devido ao fato dos conteúdos não serem direcionados para essas provas como o ENEM, já que as grades curriculares dos cursos previam que durante o último ano fossem ofertadas em sua maioria, as disciplinas de cunho técnico, o que faz com que os alunos passem praticamente um ano sem estudar as disciplinas que eram cobradas nessas provas. Vale destacar que os PPC's (projeto político pedagógico) dos cursos ora investigados sofrem mudanças nos últimos anos, sendo inclusive alterada a distribuição das disciplinas técnicas durante os quatro anos, evitando um acúmulo destas no último período do curso. Porém, deve-se dizer que a "influência negativa" vista pelos alunos não desvaloriza o formato do curso técnico, que não tem como base primordial e exclusiva a preparação desse aluno para a realização de tais provas.

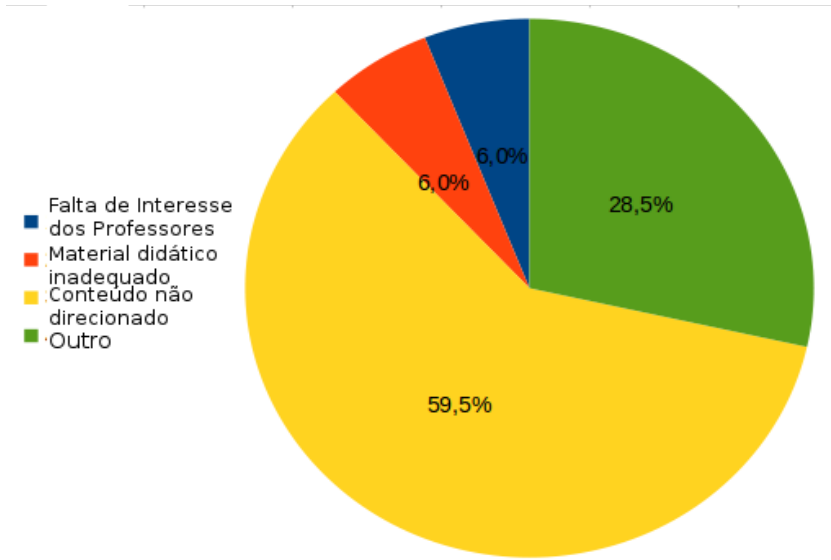

Figura 10: Contribuição negativa do IFRN no aprendizado durante o 4 ano. Fonte: Dados da pesquisa, 2015.

Em determinado momento, foi solicitado aos respondentes que elencassem sugestões e ações que pudessem auxiliá-los nessa empreitada no decorrer do 40 ano, tendo em vista que o ENEM também faz parte da realidade do aluno concluinte de um curso técnico. As sugestões mais recorrentes foram: promoção de aulões semanais, realização constante de simulados, promoção de eventos como mostra de profissões e distribuição de disciplinas técnicas ao longo dos outros 
anos, de modo que, no 4 을 ano, também haja disciplinas propedêuticas. Algumas dessas sugestões como dadas pelos alunos já foram implantadas no campus, como a realização de aulões semanais e a distribuição de disciplinas técnicas ao longo do outros anos, como já foi dito anteriormente.

Ainda nesse processo de conclusão de curso, já que as turmas investigadas estavam no 4은 ano dos cursos técnicos integrados, os alunos puderam discorrer sobre formas em que o IFRN pudesse auxiliá-los nesse momento decisivo de suas vidas estudantis. As respostas foram muito variadas, no entanto, algumas que chamaram mais atenção estão atreladas a: Palestras motivacionais, Exames vocacionais, Apoio psicológico e Diminuição da jornada acadêmica.

Até aqui foram apresentados e analisados os dados referentes à percepção dos alunos no tocante à instituição de ensino em si, com suas dificuldades e qualidades pelos alunos percebidas. A partir de então, o foco se dá na disciplina ofertada intitulada Gestão Organizacional com base numa educação empreendedora, que está intimamente ligada à formação profissional do aluno e principalmente a forma como este deve se comportar perante um mercado de trabalho tão acirrado e competitivo. Por isso, estudos como o de Rocha (2008) mostram a dificuldade enfrentada pelos jovens para se inserirem no mercado de trabalho. De forma ainda mais evidente, os dados fornecidos pelo Instituto da Cidadania (2004) estimam que a cada ano, aproximadamente 1,5 milhões de jovens buscam seu primeiro emprego, no entanto, a grande maioria não consegue se inserir de forma imediata. Prova disso é que no Brasil, em 2005, a taxa de desemprego entre os jovens chegou a 19,4\%, taxa essa muito superior a de desemprego geral que no mesmo período estava em 9,3\% (IBGE/PNAD, 2005). Outra pesquisa do PNAD, do Instituto Brasileiro de Geografia e Estatística (IBGE, 2011), também fornecem dados interessantes sobre esse assunto, como a de que a taxa de desemprego entre 15 e 24 anos de idade foi de $16,3 \%$ em 2011.

Dessa forma, vê-se a necessidade, de além da criação de postos de trabalho adequados para atender ao público jovem, a orientação desses acerca da realidade do mercado e dos meios de inserção no mesmo enquanto ainda se encontram no ambiente escolar, de forma particular por meio da disseminação do empreendedorismo tendo como base uma educação empreendedora, pois para a inserção do jovem no mercado, ter alguma experiência é mais relevante que a escolaridade. (BARBOSA FILHO e PESSOA, 2006).

Nessa perspectiva, ao serem questionados sobre a experiência com a temática empreendedorismo com base numa educação empreendedora, trabalhada na disciplina Gestão Organizacional, pode-se observar na Figura 11 que 89,6\% dos alunos consideram como Excelente ou Ótima. Assim, percebe-se que mesmo estando numa faixa etária de 17 a 19 anos, os alunos já apresentam um forte desejo de conhecer a dinâmica do mercado e o funcionamento das empresas, conhecimentos esses que propiciam ao aluno, observar e experimentar mesmo que de forma preliminar, o complexo mundo organizacional, fator decisivo que pode facilitar a inserção desses futuros profissionais no mercado, sejam como empregados e principalmente como empreendedores, uma vez que durante as aulas o aluno pode discutir e analisar, por meio do ensino, da pesquisa e extensão, experiências similares as que certamente enfrentarão fora do ambiente escolar. Ressalta-se que essas experiências serão muito úteis ao término do curso, seja para o aluno se aventurar no desafio da criação de sua própria empresa, seja para ele ingressar no mercado como um empregado qualificado e competitivo. 


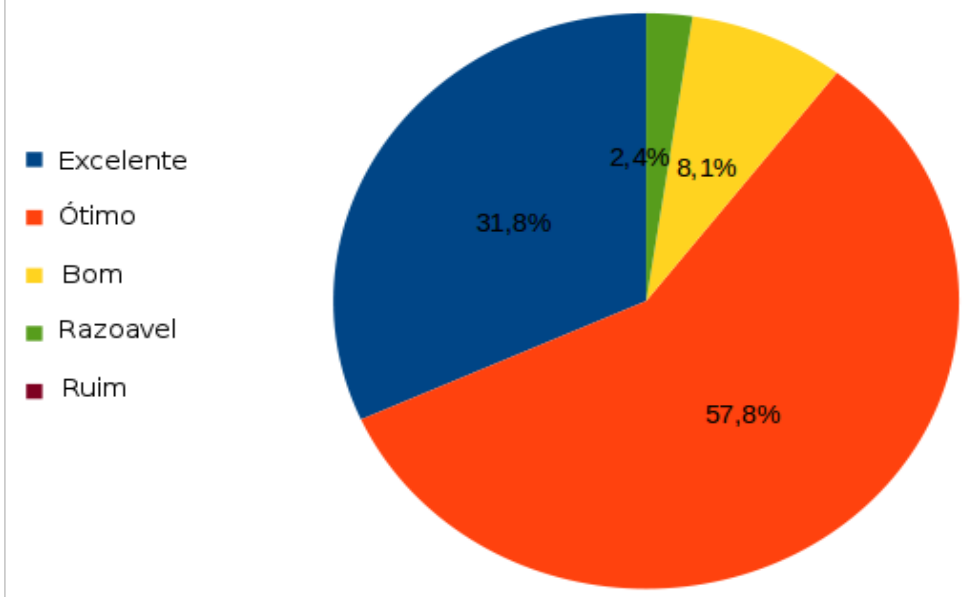

Figura 11: Importância da disciplina de Gestão Organizacional para o ensino médio e técnico Fonte: Dados da pesquisa, 2015.

Diante da grande dificuldade que envolve a inserção dos jovens no mercado, surge como alternativa a criação do seu próprio negócio, realidade bem ilustrada por Junior et. al. (2006, p. 1):

A prática do empreendedorismo mostra-se cada vez mais freqüente no Brasil como opção de carreira, frente às dificuldades socioeconômicas que assolam o país e reduzem as oportunidades para aqueles que querem ingressar no mercado de trabalho.

Todavia como bem define Boava e Macedo (2006, p. 1) "empreender representa uma ruptura com aquilo que proporciona ao ser humano segurança e estabilidade", e por vezes, falta para a grande maioria, uma força impulsionadora que pode e deve ser encontrada na escola. De fato, o Brasil é um país empreendedor, pois segundo o Global Entrepeneurship Monitor (GEM, 2005), em uma lista de 34 países, o Brasil encontra-se entre os sete com maior grau de empreendedores que abrem suas próprias empresas. Esse perfil empreendedor do brasileiro foi confirmado por pesquisa do SEBRAE (2004), que constatou que, todos os anos no Brasil, são criados cerca de 470 mil novas empresas.

Contudo, empreender no Brasil não é fácil. Analisando a definição de Barreto (1998) que afirma ser o empreendedorismo uma habilidade de criar algo a partir de pouco ou quase nada, percebe-se que essa definição se encaixa na situação do brasileiro que na prática geralmente possui pouco capital, poucos estímulos e pouca compreensão da vantagem em adquirir uma educação empreendedora como forma de obter um desenvolvimento econômico e social.

Silva (2011) mostra a necessidade de orientar e preparar o aluno para o mundo de trabalho, necessidade essa que fica bem clara a partir da observação da Figura 12 que apresenta as respostas dos alunos ao serem questionados sobre a classificação da disciplina de Gestão Organizacional, e a relevância das orientações dadas na disciplina referentes a inserção do(a) aluno(a) no mercado. A referida Figura mostra que $92,1 \%$ dos alunos consideraram a disciplina Ótima ou Excelente. 


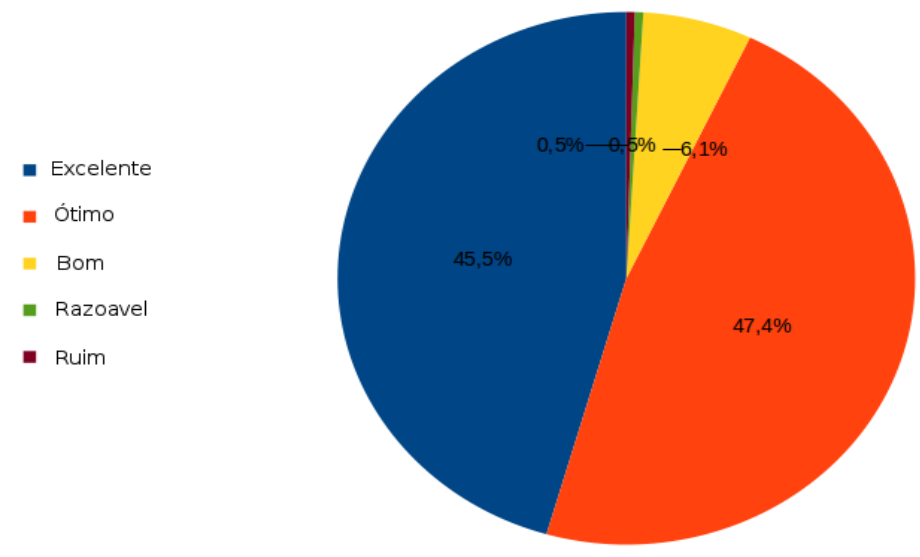

Figura 12: Relação entre a disciplina de Gestão Organizacional e a inserção no mercado de trabalho Fonte: Dados da pesquisa, 2015.

Nesse sentido, entende-se não apenas a carência dos alunos em relação a tais orientações, mas também o êxito em relação ao propósito da disciplina Gestão Organizacional do IFRN Campus Currais Novos, que tem buscado desenvolver atividades e projetos visando a construção de uma cultura empreendedora.

Em relação a outros aspectos estudados na disciplina e que foram citados pelos alunos como importantes para a vida pessoal e profissional se destacaram os seguintes:

a) Em relação ao mercado de trabalho - Adquirir conhecimento empresarial, Criação de uma empresa fictícia, Aprendizado dos modelos de produção atuais, Dinamicidade do mercado de trabalho, Conceitos de administração, Plano de negócios, Como montar o seu próprio negócio, Exemplos de empresas locais que deram certo, Marketing, Conhecimento de Instituições Filantrópicas;

b) Em relação a atitudes pessoais e profissionais - Organização do tempo, Superação do Comodismo, Inovação, Empreendedorismo, Planejamento, Comportamento profissional, Meios de inserção no mercado de trabalho, Como trabalhar em equipe, Ética, respeito e profissionalismo, Liderança, Valorização da mão de obra do técnico.

Os aspectos apontados pelos alunos podem ser vistos na descrição de Britto e Wever (2003) ao caracterizar o perfil de um empreendedor: Criatividade e inovação; Habilidade ao aplicar esta criatividade; Força de vontade e fé; e Foco na geração de valor.

Assim, de acordo com as respostas, pode-se dizer que ao confrontar o desafio da educação empreendedora, dentre eles o de fornecer um espaço que gere ao aluno a capacidade de desenvolver as características básicas do perfil empreendedor, o IFRN - Campus Currais Novos está dando passos importantes, pois mesmo sendo alunos que não tem experiências de trabalho formal e não possuem noção plenamente definida sobre o mundo dos negócios, estes relatam que a disciplina possibilitou a formação de algumas características tidas como empreendedoras.

No que se refere à percepção dos alunos quanto às exigências das empresas frente aos seus colaboradores, eles classificaram alguns itens previamente escolhidos (Qualificação técnica; Boa comunicação e interação com os demais membros da empresa; Comprometimento com os resultados da empresa; Ousadia e senso de inovação; Busca constante por novos conhecimentos; 
e Disciplina e comportamento excelentes) conforme compreendessem como mais relevante e menos relevante. Os respondentes consideraram a qualificação técnica e o comprometimento com os resultados da empresa como os itens mais importantes; e a disciplina e comportamento excelentes como o item menos importante dentro de um contexto organizacional interno.

Em relação às sugestões de melhoria apontadas pelos alunos como oportunidades de melhoria para a disciplina Gestão Organizacional, destacam-se as seguintes:

a) Dar ênfase nas leis trabalhistas;

b) Estudar a situação das empresas locais;

c) Focar nas empresas dos ramos pertencentes aos cursos técnicos alimentos e informática;

d) Dar ênfase em empreendedorismo;

e) Abordar aspectos sobre a legalização de uma empresa junto ao governo;

f) Aprofundar-se mais no marketing de uma empresa;

g) Falar sobre os impostos que uma empresa deve pagar;

h) Organizar palestras com empreendedores.

Na lista acima, pode-se tomar como exemplo dois pontos: o primeiro diz respeito à ênfase da disciplina no empreendedorismo. Vale destacar que a disciplina ministrada possui sua ementa, objetivos e conteúdo conforme o Projeto Pedagógico do Curso, que aborda não só questões relacionadas ao empreendedorismo, todavia, esse contato direto com os alunos demonstrou uma aspiração ou desejos sobre a temática, que também foi trabalhada em sala de aula sobre as diversas vertentes. Dessa forma, se tornaram perceptíveis as demonstrações de mais ações que possibilitassem o afloramento dessa cultura empreendedora, especialmente quando relacionadas aos primeiros passos na caminhada profissional como empreendedor, isto é, como dono do próprio negócio.

O segundo aspecto que vale a pena destacar nesta lista é a sugestão para que fossem promovidas palestras com empreendedores, atividades que nos anos de 2013 e 2014 foram realizadas a contento, preenchendo de certo modo essa lacuna descrita quase que exclusivamente pelos alunos do ano letivo de 2012. Nestas oportunidades, empreendedores locais foram para dentro do ambiente escolar, bem como os alunos tiveram a chance de visitar pequenas e médias empresas da região, nas quais puderam observar na prática como é o cotidiano de um empreendedor, com suas inúmeras dificuldades e incertezas enfrentadas diariamente.

Sobre a dinâmica e didática utilizada pelo professor na disciplina Gestão Organizacional, a Figura 13 revela que a maioria dos alunos considerou o desempenho satisfatório, entre bom e excelente $(15,6 \%, 42,9 \%$ e $39,5 \%$, respectivamente), o que demonstra de certa forma que os objetivos propostos pelo docente atingiu os resultados esperados. Em contrapartida, $2 \%$ dos alunos, uma porcentagem muita baixa quando comparada com o total de alunos, entende que a dinâmica da disciplina e a didática utilizada pelo professor ruim ou razoável (0,5\% e 1,5\%). 

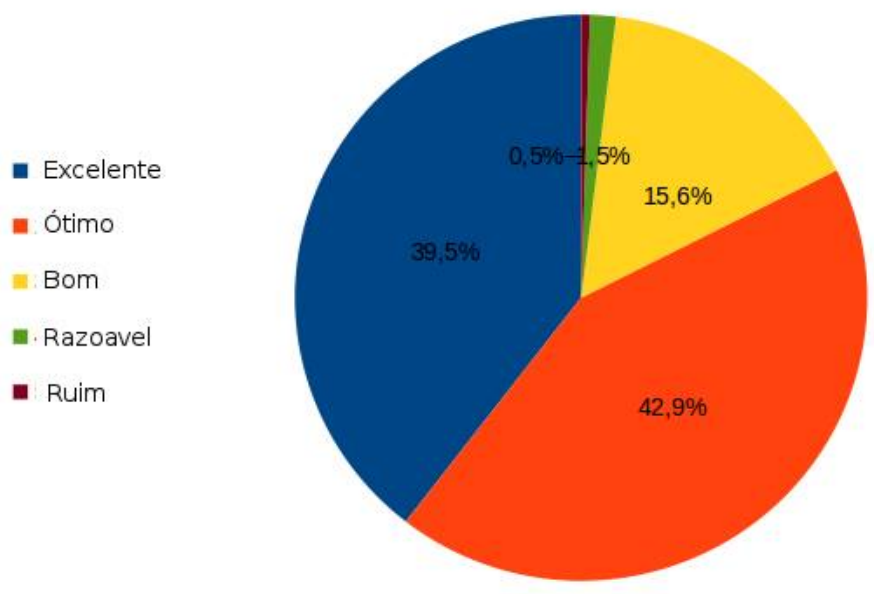

Figura 13: Dinâmica e didática utilizada pelo professor. Fonte: Dados da pesquisa, 2015.

A respeito da assimilação do conteúdo apresentado na disciplina, os resultados se mostraram bem satisfatórios, como se pode observar na Figura 14, que revela um total de 23,4\% de alunos que informa assimilar bem o conteúdo, seguido de $25,4 \%$ que entenderam ter compreendido o conteúdo de forma excelente, e $51,2 \%$ classificaram como ótimo sua compreensão da disciplina, não sendo esse quesito avaliado de forma negativa (razoável ou ruim) por nenhum discente. Assim, por meio da observação desse e das Figuras anteriores, retoma-se a questão trazida por Dolabela (1999) e outros estudiosos sobre a possibilidade de se ensinar alguém a empreender, o que neste estudo aponta para uma realidade satisfatória.

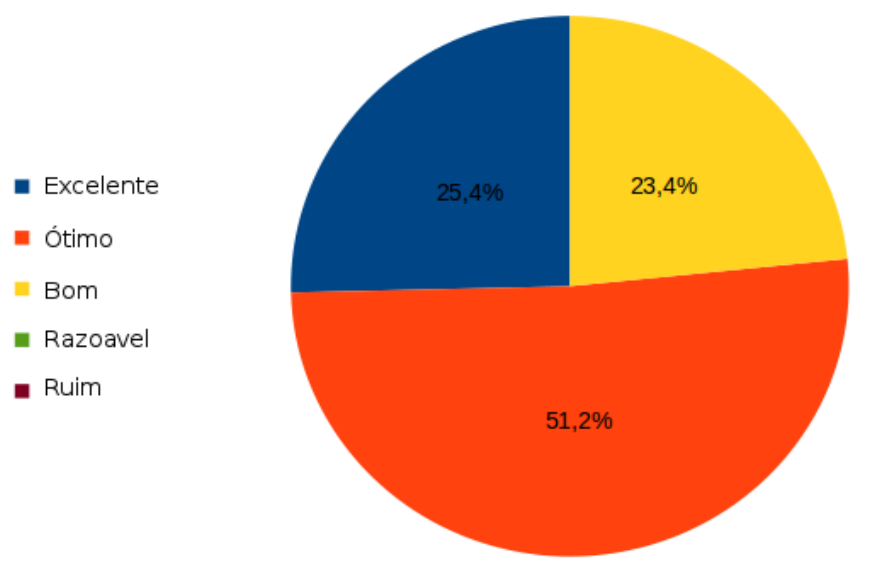

Figura 14: Assimilação do conteúdo por parte dos alunos. Fonte: Dados da pesquisa, 2015.

Sobre os pontos fortes e fracos da disciplina, foram apontados os seguintes itens:

a) Pontos fortes - Discussões constantes em sala de aula; trabalho no final da disciplina que permitiu aos alunos o contato com o plano de negócios; os conteúdos apresentados de alta relevância; a preparação oferecida pela disciplina para o mercado de trabalho; a importância do planejamento seja na esfera pessoal ou profissional; visão realista sobre a dinâmica do mercado 
de trabalho; palestras proporcionadas pela disciplina que permitiram o conto entre alunos e empreendedores da região; noções de empreendedorismo para os jovens;

b) Pontos fracos - Discussões muito amplas fugindo um pouco do foco da disciplina; baixa carga horária da disciplina; pouca valorização da disciplina por alguns alunos.

A partir dos pontos indicados pelos alunos, destacam-se alguns, a começar da percepção que obtiveram da importância do plano de negócios para qualquer empresa, caracterizando-se como uma vantagem competitiva frente a um número considerável de empreendedores, que segundo pesquisas realizadas junto a empresas de pequeno e médio porte, cerca de $66 \%$ dos entrevistados não adotam a utilização do plano de negócio ou de qualquer outro plano formal, tornando-se um fator fundamental para a grande taxa de mortalidade de empresas nos seus primeiros dois anos (JUNIOR et al., 2006).

Outro ponto importante elencado diz respeito a importância de uma formação específica para quem deseja começar seu próprio negócio, além do fato de terem entrado em contato com empreendedores de sucesso, aumentando seu networking ou rede de relacionamentos, bem como aprender dicas necessárias e relevantes para o desenvolvimento de suas próprias ideias ou negócios. Esse aspecto corrobora com o pensamento de Degen (1989) ao afirmar que a melhor forma de se obter sucesso ao iniciar um empreendimento é a imitação do sucesso alheio, técnica essa adotada pela maior parte dos empreendedores de sucesso.

Por último, os alunos perceberam que podem fazer a diferença em suas vidas como verdadeiros protagonistas, mesmo se tornando empreendedores e profissionais jovens, que apesar da pouca experiência de vida, podem sim dar passos sozinhos, substituindo a "síndrome do empregado" pelo "vírus do empreendedor" como ressalta Dolabela (1999).

Esses aspectos descritos pelos alunos a respeito da experiência que tiveram na disciplina Gestão Organizacional, com suas inúmeras atividades, podem ser a chave para o sucesso de uma educação empreendedora, pois a educação empreendedora exige que os estudantes tenham contato direto e em larga escala com a "mão na massa" e adquiram experiência com empreendedorismo e o mundo dos empreendedores (BENSON, 1993).

Por último, abaixo se encontram algumas transcrições diretas dos relatos de alguns alunos a respeito da experiência obtida durante as aulas da disciplina Gestão Organizacional que buscou pautar sua didática e dinâmica de acordo com os princípios de uma educação empreendedora. Os relatos demonstram que os conhecimentos adquiridos e as experiências vividas poderão ajudar sobremaneira em suas vidas pessoais e profissionais:

"A disciplina ampliou a visão de mundo que eu tinha em relação ao mercado de trabalho." (Aluno A),

"O curso prepara para o mercado de trabalho, essa disciplina ensina como ele funciona." (Aluno B),

"Com certeza, porque essa disciplina fez com que o aluno se imagine atuando no mercado de trabalho. E amplia o conhecimento sobre gestão." (Aluno C), 
"Sim, na vida pessoal, a disciplina me ajudou a ter uma maior organização e adquirir bons valores e criatividade. Na minha vida profissional também me auxiliou na questão da organização e ampliou minha visão de mercado.", (Aluno D),

"Certamente sim, pois a partir da disciplina, dos exemplos podemos aprender como criar de maneira correta uma empresa e as dificuldades, que são vistas na criação de uma nova empresa, podemos então, assimilar a realidade e então quem sabe um dia utilizarmos o que aprendemos no mercado de trabalho." (Aluno E),

"Sim, principalmente no momento em que eu for montar minha empresa pois quando isso acontecer vou ter que recorrer aos conhecimentos obtidos na disciplina." (Aluno F),

"Ajudarão a me comportar e me localizar melhor em empresa e ambientes de trabalho. Além disso a disciplina desperta o desejo de querer fundar o próprio negócio." (Aluno G).

Os relatos dos alunos em si já revelam o quanto foi interessante o trabalho desenvolvido na disciplina Gestão Organizacional que abordou diversos conteúdos, dentre eles o empreendedorismo, com base numa educação empreendedora.

\section{CONCLUSÃO}

O estudo ora apresentado buscou diagnosticar a percepção dos alunos dos cursos técnicos integrados de nível médio do IFRN - Campus Currais Novos em relação às suas experiências no IFRN - Campus Currais Novos, dentre estas, com a disciplina Gestão Organizacional ministrada com base numa educação empreendedora, na qual diversas ações e atividades tentaram proporcionar uma dinâmica diferenciada aos alunos em prol de um melhor aproveitamento do conteúdo transmitido e principalmente das experiências vivenciadas. Desse modo, percebeu-se que os alunos pesquisados consideram satisfatória a disciplina ministrada, bem como a didática utilizada pelo docente, isto é, compreendem como instigante e proveitoso o estudo sobre empreendedorismo, principalmente quando baseado numa educação empreendedora.

Nesse contexto, espera-se que estudos posteriores sejam realizados em outras turmas de níveis diferentes, como no ensino superior e no curso integrado na modalidade de educação para jovens e adultos ou então que pesquisas realizem comparações entre disciplinas ou cursos que utilizam a educação empreendedora como prioridade e outras que não utilizam, além de comparações entre cursos semelhantes ou distintos em campi diferentes da rede federal de educação profissional.

Por fim, ressalta-se novamente a relevância dessas práticas baseadas na educação empreendedora, bem como do assunto empreendedorismo em si, que além de trazer novidades temáticas para os discentes, os envolve em assuntos pertinentes ao seu futuro profissional, independente da área em que atuem.

\section{REFERÊNCIAS}

Barbosa, F. H., Filho \& Pessoa, S. (2006). Retorno da educação no Brasil. São Paulo: Instituto Futuro Brasil. 
Barreto, L. P. (1998). Educação para o empreendedorismo. Salvador: Escola de Administração de Empresas da Universidade Católica de Salvador.

Benson, G. L. (1993). Thoughts of an entrepreneurship chairholder model entrepreneurship curriculum. Journal of Applied Business Research, 9(1).

Boava, D. L. T., \& Macedo, F. M. F. (2006). Estudo sobre a essência do empreendedorismo. Anais do Encontro Nacional da Associação Nacional de Pós Graduação e Pesquisa em Administração, Salvador, BA, 30.

Brasil, Ministério da Educação. (2016) Expansão da Rede Federal. Brasília: Ministério da Educação. Disponível em: <http://redefederal.mec.gov.br/expansao-da-rede-federal>. Acesso em: 18 Abr. 2016.

Britto, F., \& Wever, L. (2004). Empreendedores brasileiros: a experiência e as lições de quem faz acontecer. Rio de Janeiro: Elsevier.

Bulgacov, Y. L. M., et al. (2010). Jovem empreendedor no Brasil: a busca do espaço da realização ou a fuga da exclusão? Revista de Administração Pública, 45(3).

Degen, R. J. (1989). O empreendedor: fundamentos da iniciativa empresarial. São Paulo: McGrawHill.

Dolabela, F. (1999). O Ensino de Empreendedorismo no Brasil: Uma Metodologia Revolucionária. São Paulo: Fundação Vanzolino.

(1999). Oficina do Empreendedor: A metodologia de ensino que ajuda a transformar conhecimento em riqueza. São Paulo: Cultura Editores Associados.

Dolabela, F., \& Filion, L. J. (2013). Fazendo revolução no Brasil: a introdução da pedagogia empreendedora nos estágios iniciais da educação. Revista de Empreendedorismo e Gestão de Pequenas Empresas, 3(2).

Drucker, P. F. (1986). Inovação e Espírito Empreendedor: Prática e Princípios. São Paulo: Cengage Learning.

Filion, L. J. (1991). O planejamento do seu sistema de aprendizagem empresarial: Identifique uma visão e avalia o seu sistema de relações. Revista de Administração de Empresas, FGV, São Paulo, jul./set.

. (1993). Visão e relações: elementos para um metamodelo empreendedor. Revista de Administração de Empresas, 33(6).

- (1999). Diferenças entre sistemas gerenciais de empreendedores e operadores de pequenos negócios. Revista de Administração de Empresas, 39(4).

. (2003). Um roteiro para desenvolver o empreendedorismo. Recife: IEL.

. (2004). Operators and visionaries: differences in the entrepreneurial and managerial systems of two types of entrepreneurs. International Journal of Entrepreneurship and Small Business, 1(1), pp. 35-55.

Global Entrepreneurship Monitor. (2005). Empreendedorismo no Brasil 2004: Sumário Executivo. Curitiba: SEBRAE.

Gomes, et al. (2014). Empreendedorismo Jovem: da escola para o mercado de trabalho. Revista Holos, 5(30). 
Hengemüle, A. (2014). Desafios educacionais na formação de empreendedores. Porto Alegre: Penso.

Instituto Brasileiro de Geografia e Estatística [IBGE]. (2005). Pesquisa Nacional por Amostra de Domicílios (PNAD). Brasília.

Instituto Brasileiro de Geografia e Estatística [IBGE]. (2011). Pesquisa Nacional por Amostra de Domicílios (PNAD). Brasília.

Instituto da Cidadania. (2004). Projeto Juventude - versão inicial para discussão, complementação e ajustes. São Paulo.

Junior, J. B. C., et. al. (2006). Empreendedorismo e educação empreendedora: confrontação entre a teoria e prática. Ciências da Administração, 8(15).

Lima-Filho, D. O., Sproesser, R. L., \& Martins, E. L. C. Empreendedorismo e Jovens Empreendedores. (2009). Revista de Ciências da Administração, 11(24).

Lopes, R. M. A. (2010). Educação empreendedora: conceitos, modelos e práticas. Rio de Janeiro: Elsevier.

Mendes, J., \& Filho, I. Z. (2012). Empreendedorismo para Jovens: ferramentas, exemplos reais e exercícios para alinhar a sua vocação com o seu projeto de vida. São Paulo: Atlas.

Rocha, S. (2008). A Inserção dos Jovens no Mercado de Trabalho. Caderno CRH, 21(54).

SEBRAE. (2004). Fatores condicionantes de taxa de mortalidade de empresas no Brasil. Relatório de Pesquisa. Brasília: SEBRAE.

Silva, M. A. B. (2011). Jovens Adolescente e a Inserção ao Mundo de Trabalho: Influências e Percepções. Anais do Congresso Luso Afro Brasileiro de Ciências Sociais, Salvador, BA, Brasil, 11. 